American Journal of Pharmaceutical Education 2019; 83 (8) Article 7027.

\title{
RESEARCH
}

\section{An Elective Course to Train Student Pharmacists to Provide Culturally Sensitive Health Care}

\author{
Sally Arif, PharmD, ${ }^{a}$ Sheila Wang, PharmD, ${ }^{a}$ Irfana Y. Lakada, PharmD, ${ }^{b}$ Jane Y. Lee, PharmD \\ ${ }^{a}$ Chicago College of Pharmacy, Midwestern University, Downers Grove, Illinois \\ ${ }^{\mathrm{b}}$ Beaumont Hospital, Dearborn, Michigan \\ ${ }^{c}$ AbbVie Pharmaceuticals, North Chicago, Illinois
}

Submitted February 19, 2018; accepted August 19, 2018; published October 2019.

Objective. To design and implement an elective course that prepares student pharmacists to provide culturally sensitive health care by developing their knowledge, self-confidence, and clinical and communication skills for working with patients from various cultural backgrounds during community health screenings.

Methods. In this one-credit-hour elective course, second- and third-year pharmacy students were taught about chronic disease states affecting various minorities, approaches to improve their communication with patients from various cultural backgrounds, and proper use of cardiometabolic equipment during health screening events. After a health screening event at the end of the course, knowledge scores, self-confidence, clinical skills, and communication skills were compared between students who took the elective course and those in a control group. A pre-post elective survey was administered to second- and third-year students enrolled in the elective course to assess differences in understanding, self-confidence, clinical skills, and communication skills.

Results. The 31 students who completed the elective course performed better on the knowledge quiz questions than did the 31 students in the control group (response rate 100\%). Self-confidence, and communication and clinical skills scores were higher among those who completed the elective course than those who did not. There was an increase in knowledge scores for all students enrolled in the course. Second-year students were just as confident in their abilities as third-year students by the end of course.

Conclusion. An elective course focused on better preparing students to provide culturally sensitive health awareness through community health screenings improved students' overall knowledge, clinical skills, communication skills, and self-confidence.

Keywords: cultural competency, health promotion, clinical skills

\section{INTRODUCTION}

Given an increasingly diverse US population, it is important to prepare pharmacy students to engage effectively with different cultures. Pharmacist-run health screenings in the community setting are a means to detect disease early and provide an accessible point of care for patients. ${ }^{1}$ Furthermore, health screenings are an opportunity to educate the public regarding common chronic disease conditions as well as to promote the expanding roles of the pharmacist. ${ }^{2,3}$ Providing health screenings to local minority groups, which are typically underserved, is a common avenue for student pharmacists to be involved in their com-

Corresponding Author: Sally Arif, Chicago College of Pharmacy, Midwestern University, $55531^{\text {st }}$ St., Downers Grove, IL 60605. Tel: 630-515-6466. E-mail: sarif@midwestern.edu munity. ${ }^{1}$ Students are given the opportunity to apply the knowledge they learn in the classroom to real-life scenarios. Conducting health screening has also become an encouraged addition to the academic coursework at many colleges of pharmacy as a means to meet service-learning and cocurricular requirements per the Accreditation Council for Pharmacy Education (ACPE) standards. ${ }^{4}$ Additionally, such involvement also fulfills the guidance requested through the American Association of Colleges of Pharmacy (AACP) Center for the Advancement of Pharmacy Education (CAPE) outcomes ${ }^{5}$ with respect to strategies in managing chronic diseases and improving health and wellness, influencing the population to engage in patient-centered care with awareness of practice guidelines and evidencebased best practices, and recognizing social determinants of health to improve access to care. 


\section{American Journal of Pharmaceutical Education 2019; 83 (8) Article 7027.}

Typically, during community health screenings, student pharmacists perform blood pressure, glucose, and cholesterol monitoring, as well as educate patients on their further health needs under the supervision of a licensed pharmacist. Student pharmacists commonly feel more confident in their ability to communicate more effectively with patients after participating in health screenings. ${ }^{2}$ However, many health professional students who volunteer to for health screenings receive limited training prior to an event which usually only consists of practice using the screening devices and orientation to generic medical educational information. ${ }^{3}$ Variability in student learning and a lack of emphasis in the curriculum on tailoring health education to various patient groups makes it unlikely that the majority of students receive sufficient training before participating in health screening events. Threatt and colleagues recognized student deficiencies related to necessary knowledge and skills and thus developed test-specific training modules at the Presbyterian School of Pharmacy in South Carolina for a variety of health screenings. ${ }^{6}$ The authors found that $92.8 \%$ of students agreed or strongly agreed the training modules improved their confidence and performance in conducting tests. Additionally, nearly $88 \%$ agreed or strongly agreed they would not have been adequately prepared to conduct the health test without the training. This sequential training model reinforces the benefit of standardizing the education and training student pharmacists receive, thereby providing better health services to patients.

While several studies have described the positive impact of student participation in cardiovascular risk-reduction screening events, there is no evidence evaluating the training of students to effectively work with minority groups who are known to have language barriers and low health literacy. Very few studies describe how health screening training programs prepare students to navigate cultural differences during screening events. ${ }^{3,7}$ This becomes crucial as underserved minorities are disproportionately affected by poor quality of health care, which includes access to care and receipt of needed medical care. ${ }^{4,8,9}$

The literature demonstrates there is a need to address the gap in training of health professions students and identify methods to better prepare students to provide culturally sensitive care when promoting health and disease prevention in the community. This requires a formal assessment of students' ability to use screening equipment, think critically, identify risk factors, and communicate effectively with patients from a variety of cultural backgrounds. The primary objective of this study was to implement and evaluate an elective course that prepares student pharmacists to provide culturally sensitive health awareness by developing their knowledge, self-confidence, and their clinical and communication skills when working with patients from various cultural backgrounds during community health screenings.

\section{METHODS}

Health Promotion and Disease Prevention Across Cultures was a one-credit hour elective course created for second- and third-year pharmacy students at Midwestern University Chicago College of Pharmacy. The elective course was designed to be delivered over six weeks and consisted of lectures, workshop sessions, a simulated health screening of a patient, and participation in a community health-screening event. Course enrollment was capped at 35 students to facilitate in-class discussion and hands-on learning activities. The first hour of class was dedicated to lecture and a half-hour to a handson workshop focused on practicing clinical and communication skills. The lecture portion reintroduced course specific disease states taught during the required pharmacotherapeutics course, such as hypertension, diabetes, and hyperlipidemia, with the added objective of recognizing the influences of patients' varying ethnic backgrounds and cultures. Risk factors for common disease states, screening techniques, evidence-based goals of therapy, and counseling points on lifestyle modifications with a focus on cultural sensitivity were also discussed. The workshops consisted of training with regards to the use of screening instruments, such as a sphygmomanometer, stethoscope, glucometer, body mass index (BMI) machine, and cholesterol testing device. During each weekly workshop, a second-year student was randomly partnered with a third-year student to practice using cardiometabolic devices and apply their cross-cultural interviewing skills. Students were expected to introduce themselves to their partners and share their cultural health beliefs with one another. They were also encouraged to ask open-ended questions to evaluate each other's medical history (eg, age, past medical history, smoking status, family history, medications), interpret screening results, and counsel their partner about culturally appropriate lifestyle changes, such as diet and exercise.

A simulated health screening with a standardized patient was required as part of the students' final assessment in the course. Actors were recruited to play the patients and were provided with scripts to memorize prior to the event. Scripts included their past medical history, social history, medications, and pertinent cultural health beliefs and concerns to relay to the student only if asked. Each student was given 10 minutes to interview a patient 


\section{American Journal of Pharmaceutical Education 2019; 83 (8) Article 7027.}

in a culturally sensitive manner, identify risk factors, display correct technique when using point-of-care devices, accurately interpret the patient's screening results, and provide culturally appropriate counseling points. Students were randomly assigned to one of four rooms at the time of their simulated patient encounter. Each room had a unique patient and screening task (room 1: AfricanAmerican female patient requesting a blood pressure screening; room 2: Asian-American female patient requesting a blood glucose screening; room 3: IndianAmerican male patient requesting a blood glucose screening; and room 4: Middle Eastern female patient requesting a blood pressure screening). An additional five minutes was allowed after the patient encounter for the pharmacist evaluator in the room to provide the student with verbal feedback.

A longitudinal survey was administered to elective student pharmacists before and after the course. A control group of student pharmacists who did not complete the elective course was used for comparison, and case matched by year of study and gender. The students who took the elective course completed both the pre- and postcourse survey, while the students in the control group only completed the post-course survey. Post-course survey results were compared between the elective course students and students in the control group after the community health screening. The survey instrument consisted of baseline demographics, a 12-question quiz assessing disease state knowledge, and 13 self-assessment questions to measure students' self-perceived confidence. Quiz questions to assess disease state knowledge were adapted from examination questions that had been vetted and approved by faculty members and included in examinations administered during the required pharmacotherapeutics and clinical skills courses. At the time of the study, no instruments existed that measured the self-confidence of pharmacy students with regard to their intervention of culturally sensitive disease state knowledge and skills. Therefore, a self-perceived approach to assess confidence about disease-state knowledge, application of skills, comfort using screening equipment, and provision of culturally sensitive care was evaluated by participating students using a quantitative Likert-type scale $(1=$ strongly disagree to $6=$ strongly agree). There was required coursework dedicated to developing students' communication and clinical skills in the third year of the Midwestern University curriculum. Therefore, skills, knowledge, and confidence were compared between second- and third-year students in the elective group to evaluate the impact of the timing of the elective within the curriculum.

Clinical and communication skills were evaluated using a rubric that captured each student's ability to use the knowledge and skills they acquired from the course. The criteria used to evaluate each student was based on learning objectives from the course. This rubric was used by supervising pharmacists during the simulated health screening patient encounter, as well as for students in both the elective course and control group at the community health screening encounter at the end of the course.

Supervising pharmacists were selected based on their extensive experience working with underserved or minority patients in the community setting. The course directors for the elective course delivered a one-hour training workshop to the pharmacists prior to the screening event. This workshop was meant to orient the evaluators to the rubric, discuss potential barriers to communication in cross-cultural interactions, and review screening techniques discussed in the course. A grocery store with an onsite pharmacy located in an ethnically diverse (white, Asian, Eastern-European, and Latino) neighborhood of Chicago was selected as the site for the community health-screening event. This site was selected to increase the diversity of patient encounters and give students the opportunity to practice adapting their crosscultural communication and clinical skills to patients from various ethnic and racial backgrounds in the community.

At the community health screening event, students were observed and evaluated by the pharmacist as they screened a patient for either blood pressure or blood glucose. Students were assessed in the following areas: collecting pertinent history to assess for risk factors (eg, age, smoking status, family history, history of disease, diet), identifying patient specific risk factors, correctly performing screening tests, correctly interpreting the test results, and counseling the patient in a culturally sensitive manner based on the patient's lifestyle and health beliefs. Students' clinical skills were evaluated on a six-item assessment using a four-point Likert scale that ranged from $1=$ student required extensive intervention or exhibited skill below minimum competency to $4=$ student required no intervention or exhibited skill well above minimum competency. Communication skills were evaluated categorically based on whether the student did or did not demonstrate appropriate verbal and nonverbal communication during the encounter. For all skills, performance scores were compared between students who took the elective course and those in the control group and between second-year and third-year students who took the elective course.

This study was approved by the Midwestern University Institutional Review Board. Statistical analyses were performed using SPSS 22 (IBM, Chicago, IL). Descriptive data summaries were conducted using frequencies for 


\section{American Journal of Pharmaceutical Education 2019; 83 (8) Article 7027.}

categorical variables and means for quantitative variables, including knowledge scores. Bivariate analysis was conducted by using independent samples $t$ test, paired $t$ test, chi square, and McNemar chi square. Multivariate analysis was conducted via simultaneous estimation techniques, including multiple regression and multiple logistic regression. All tests were conducted at a .05 nominal significance level.

\section{RESULTS}

Thirty-one students completed the elective course and participated in the community health screening (mean age 25.4 years, $\mathrm{SD}=4.9$ years; $37.5 \%$ self-reported as white). An equal number $(n=31)$ of students (mean age $=26$ years, $\mathrm{SD}=5.7$ years; $22.6 \%$ self-reported as white) did not take the elective course but did participate in the community health screening. Both the elective and non-elective students had equal ratios of second-year $(n=15)$ and third-year students $(n=16)$. Both study groups consisted of mostly female students $(65.6 \%$ for both elective course and control group students). Postknowledge assessment scores among students who completed the elective course were slightly higher than those of students in the control group ( $74.2 \%$ vs $68.3 \%$ correct, respectively), but not significantly different $(p=.07)$. Among students enrolled in the elective course, there was a significant increase in knowledge by the end of the course (pre-course $=66.4 \%$ vs post-course $=74.2 \%$ correct, $p=.03$ ). No difference in knowledge scores was observed between second-year and third-year students by the end of the elective (post-course $=77.3 \%$ correct vs post-course $=71.3 \%$ correct, respectively, $p=.16$ ).

Students who completed the elective course were more confident regarding their disease state knowledge and application of knowledge pertaining to diabetes, hypertension, and dyslipidemia than students who did not take the elective course $(p<.05$, Table 1$)$. Students who completed the elective course also felt more confident in the use of a blood glucose and cholesterol meter than did students in the control group, but students in both groups displayed similar confidence in the use of a manual blood pressure cuff and stethoscope $(p=.56)$. Students who completed the elective course had more confidence in their knowledge of other beliefs and cultural health practices and more appreciation for the importance of providing culturally competent care and inquiring about a patient's cultural background than did students in the control group $(p<.05)$. However, self-perceived confidence in

Table 1. Comparison of Self-Confidence Scores Between Student Pharmacists Who Completed an Elective Course in Culturally Sensitive Health Care Versus a Control Group, and Between Second- and Third-Year Students

\begin{tabular}{|c|c|c|c|c|}
\hline \multirow[b]{2}{*}{ I feel confident in. . . } & \multicolumn{4}{|c|}{ Student Pharmacists' Confidence Levels, Mean (SD) ${ }^{\mathrm{a}}$} \\
\hline & $\begin{array}{l}\text { Elective Course, } \\
(\mathbf{n}=\mathbf{3 1})\end{array}$ & $\begin{array}{l}\text { Control Group, } \\
\quad(\mathrm{n}=\mathbf{3 1})\end{array}$ & $\begin{array}{l}\text { Second-Year, } \\
\quad(n=15)\end{array}$ & $\begin{array}{l}\text { Third-Year, } \\
\quad(n=16)\end{array}$ \\
\hline my knowledge of hypertension. ${ }^{\mathrm{b}}$ & $5.1(0.5)$ & $4.2(0.9)$ & $4.7(0.6)$ & $5(0.6)$ \\
\hline my knowledge of diabetes. & $4.9(0.8)$ & $4(1.1)$ & $4.4(0.9)$ & $5(0.6)$ \\
\hline my knowledge of dyslipidemia. ${ }^{\mathrm{b}}$ & $4.9(0.7)$ & $4.0(0.8)$ & $4.6(0.7)$ & $4.7(0.8)$ \\
\hline $\begin{array}{l}\text { applying my knowledge of hypertension to an } \\
\text { individual patient. }\end{array}$ & $5(0.6)$ & $4.2(0.9)$ & $4.8(0.7)$ & $4.8(0.7)$ \\
\hline $\begin{array}{l}\text { applying my knowledge of diabetes to an } \\
\text { individual patient. }\end{array}$ & $4.9(0.8)$ & $4(1.1)$ & $4.4(1.0)$ & $4.9(0.7)$ \\
\hline $\begin{array}{l}\text { applying my knowledge of hyperlipidemia to } \\
\text { an individual patient. }\end{array}$ & $4.8(0.7)$ & $3.9(0.8)$ & $4.4(0.8)$ & $4.6(0.8)$ \\
\hline using sphygmomanometer and stethoscope. ${ }^{c}$ & $4.9(0.8)$ & $4.8(1.0)$ & $4.6(0.9)$ & $5.2(0.7)$ \\
\hline using a blood glucose meter. ${ }^{\mathrm{b}}$ & $5.5(0.6)$ & $5.1(0.8)$ & $5.3(0.7)$ & $5.3(0.7)$ \\
\hline using a cholesterol meter. ${ }^{\mathrm{b}}$ & $4.7(0.9)$ & $3.7(1.3)$ & $4(1.3)$ & $4.6(0.9)$ \\
\hline $\begin{array}{l}\text { counseling a patient from a different cultural } \\
\text { background than me. }\end{array}$ & $4.8(0.6)$ & $4.6(1.0)$ & $4.9(0.7)$ & $4.7(0.7)$ \\
\hline providing culturally competent care to patients. ${ }^{\mathrm{b}}$ & $5.1(0.6)$ & $4.6(0.8)$ & $4.9(0.7)$ & $4.9(0.7)$ \\
\hline $\begin{array}{l}\text { in my knowledge about beliefs and health } \\
\text { practices of cultural groups different than mine. }\end{array}$ & $5(0.7)$ & $4.6(1.0)$ & $4.9(0.9)$ & $4.8(0.8)$ \\
\hline $\begin{array}{l}\text { in asking a patient questions about their cultural } \\
\text { practices or background. }\end{array}$ & $5.3(0.6)$ & $4.7(1.0)$ & $5.2(0.6)$ & $5.4(0.6)$ \\
\hline
\end{tabular}




\section{American Journal of Pharmaceutical Education 2019; 83 (8) Article 7027.}

their ability to counsel patients from different cultural backgrounds did not differ significantly between students in the elective course and those in the control group. There was no difference in self-confidence between second and third-year students who completed the elective course, with the exception of knowledge of diabetes and use of a blood pressure cuff and stethoscope, for which thirdyear students had more self-assurance by the end of the course $(p<.05)$.

Overall, clinical and communication skills (Table 2 and Table 3) were better among students who completed the elective-course than students in the control group $(p<.05)$. Elective course students more often tailored their counseling points to align with patients' specific health preferences and more often inquired about patients' health beliefs during the patient encounters than did students in the control group $(p<.05)$. No difference was found in instrument technique as both elective-course and control group students displayed correct technique $(p=.56)$; however, third-year students performed significantly better than second-year students $(p=.02)$.

\section{DISCUSSION}

With the growing underserved minority population in the United States and the expanding role of pharmacists to provide community-based disease education and prevention, offering courses that enhance students' ability to address the healthcare needs of this population is essential. Implementation of this course provided a holistic approach to preparing students to provide culturally sensitive care by focusing on building students' confidence, skills, and knowledge. Promoting health and disease pre- vention among underserved minority groups can be overwhelming for students, but such a course can highlight practical approaches student pharmacists can apply to engage in patient care and diversify the role of the pharmacist. The students who completed the course demonstrated: improved confidence when interacting with patients from underserved populations and effective communication and clinical skills compared to students who did not take the elective course. Also, students' knowledge about culturally sensitive care improved after completing the elective course. This aligns with literature that suggests cultural competence training positively impacts the knowledge of healthcare providers. ${ }^{10}$ However, to our knowledge this is the first study to incorporate cultural sensitivity training for health care professions students in the context of cardiometabolic community health screenings.

The results support a standardized training approach for students who plan to participate in pointof-care screening events targeting minorities. The course also demonstrated pedagogical methods that can enhance cultural competency training within the pharmacy curriculum. However, the placement of such a course within the curriculum should take into account when other required communication and clinical skillsbased courses are being taught. We found there was a significant increase in knowledge for all students after completing the elective course, regardless of what professional year they were in. However, with regard to self-confidence, second-year students demonstrated less comfort in areas of therapeutic knowledge (eg, diabetes) and blood pressure measurement technique by

Table 2. Clinical Skills Assessment Scores Between Student Pharmacists Who Completed an Elective Course in Culturally Sensitive Health Care Versus a Control Group and Between Second- and Third-Year Students

\begin{tabular}{|c|c|c|c|c|}
\hline \multirow[b]{2}{*}{ Criteria Evaluated } & \multicolumn{4}{|c|}{ Student Pharmacists, Mean (SD) } \\
\hline & $\begin{array}{l}\text { Elective Course, } \\
\qquad(n=31)\end{array}$ & $\begin{array}{l}\text { Control Group, } \\
\quad(n=31)\end{array}$ & $\begin{array}{l}\text { Second-Year, } \\
\quad(n=15)\end{array}$ & $\begin{array}{l}\text { Third-Year, } \\
\quad(n=16)\end{array}$ \\
\hline $\begin{array}{l}\text { Had an accurate interpretation of results and correctly } \\
\text { identified and relayed if patient was at/above goal. }\end{array}$ & $3.9(0.3)$ & $3(1.0)$ & $3.9(0.4)$ & $3.9(0.3)$ \\
\hline $\begin{array}{l}\text { Gave accurate information when counseling, and included } \\
\text { at least two lifestyle recommendations. }\end{array}$ & $3.7(0.7)$ & $1.6(0.9)$ & $3.4(0.8)$ & $3.9(0.3)$ \\
\hline $\begin{array}{l}\text { Demonstrated a solid understanding of the patient's disease } \\
\text { state(s) screened. }\end{array}$ & $3.6(0.7)$ & $1.9(0.8)$ & $3.5(0.7)$ & $3.7(0.6)$ \\
\hline $\begin{array}{l}\text { Tailored counseling to the patient's health preferences based } \\
\text { on their cultural beliefs/ practices/background. }{ }^{\text {a }}\end{array}$ & $3.7(0.6)$ & $1.3(0.5)$ & $3.5(0.8)$ & $3.9(0.3)$ \\
\hline
\end{tabular}




\section{American Journal of Pharmaceutical Education 2019; 83 (8) Article 7027.}

Table 3. Communication Skills Assessment Scores of Student Pharmacists Who Completed an Elective Course in Culturally Sensitive Health Care Versus a Control Group and Between Second- and Third-Year Students

\begin{tabular}{|c|c|c|c|c|}
\hline \multirow[b]{2}{*}{ Criteria Evaluated } & \multicolumn{4}{|c|}{ Student Pharmacists, No. (\%) } \\
\hline & $\begin{array}{l}\text { Elective Course, }^{\mathrm{c}} \\
(\mathrm{n}=\mathbf{3 1})\end{array}$ & $\begin{array}{l}\text { Control Group, } \\
\quad(n=31)\end{array}$ & $\begin{array}{l}\text { Second-Year, } \\
\quad(n=15)\end{array}$ & $\begin{array}{l}\text { Third-Year, } \\
\quad(n=16)\end{array}$ \\
\hline $\begin{array}{l}\text { Communicated effectively (eg, no medical jargon, } \\
\text { clear instructions, asked for interpreter if needed). }\end{array}$ & $26(83.9)$ & $23(74.2)$ & $12(75)$ & $15(93.8)$ \\
\hline $\begin{array}{l}\text { Displayed good eye contact and body language } \\
\text { (faced patient squarely, open body posture and no } \\
\text { distracting gestures). }\end{array}$ & $28(90.3)$ & $25(80.7)$ & $16(100)$ & $16(100)$ \\
\hline
\end{tabular}

the end of the course when compared to their third-year counterparts. This phenomenon may have been because of their lower baseline comfort, understanding of cardiometabolic screening tools, and practice with patient encounters at the time this elective was offered. This may suggest a steeper learning curve for students in such a course if it is placed earlier in the curriculum. Future directions include offering this elective to only third-year students because of their greater aptitude for using cardiometabolic devices, which would leave more time to spend on building their cultural competency and communication skills.

Both students enrolled in the elective course and those in the control group felt highly confident in asking patients about their cultural practices or background. However, the ability to tailor counseling to the patient's preferences based on their cultural health beliefs and background was more often demonstrated by students who completed the elective course. This may have been because of the course's overarching objective for students to think critically and problem solve when presented with patients from varying backgrounds at community health screenings. At the end of the course, students noted various factors that contributed to their positive learning experience, such as having the weekly opportunity for "hands on learning with the testing devices," "chance to practice my interviewing skills with my peers," and "learning about others' health beliefs." Expanding the elective to more credit hours might allow time for more patient simulations to be incorporated so students could practice their cultural skills more. This could contribute to building both student confidence and cultural awareness by exposing students to a greater variety of patient encounters.
Faculty workload and cost of materials should be considered prior to implementing such an elective. Substantial time was dedicated to recruiting supervising pharmacists and orienting them to the grading rubric prior to having them evaluate students' knowledge and skills during the health screening events. To eliminate any evaluator bias, the pharmacists were blinded to which students were enrolled in the elective or what concepts were taught during the course. The simulated health screening required creating scripts for each encounter and hiring actors to play standardized patients from various cultural backgrounds. The standardized patients were required to learn about the cultural background and belief system of the patient they were portraying and standardize their responses for each student during the encounters. For the lecture component, outside speakers representing various minority groups were brought in to discuss health practices and beliefs and facilitators were also solicited to help run the workshops. Also, finding facilitators with extensive experience in working with underserved minority groups could be a potential limitation for replicating this elective course and health screening event in areas without diverse networks. Finally, the costs of hosting a health screening event can be significant. We were able to secure an intramural educational grant to cover the cost of point-of-care devices, test strips, and supplies for each of the weekly workshops.

The results of this study should be considered with the following limitations in mind. The study was conducted at one private school of pharmacy in the Midwest. The small size and narrow demographics of our student population may not represent student populations across the country. We anticipated that students who had a stronger interest in improving their cultural 


\section{American Journal of Pharmaceutical Education 2019; 83 (8) Article 7027.}

competency or prior experience with health screenings would enroll in the elective course, which may have resulted in a higher baseline knowledge and skill set among those who enrolled compared to students who do did not enroll in the course. Also, the questions on the quiz that assessed student knowledge may not have been rigorous enough to detect a difference in understanding between students who had completed the elective course and those who had not. Although a significant change was found in scores on multiple items, we could not determine whether these changes would translate into meaningful or relevant differences in student confidence or skills in practice as our survey tool had not been validated. Further research is needed to develop a comprehensive tool to validate relevant measurements of student confidence regarding knowledge and application of clinical skills when providing culturally sensitive care.

\section{CONCLUSION}

An elective course focused on providing culturally sensitive care when promoting health and disease prevention among underserved minority groups was able to improve student confidence, knowledge, communication, and clinical skills. Students enrolled in the elective course were more confident and showed greater improvement in overall skills and knowledge than did students who did not take the elective course.

\section{REFERENCES}

1. Raney, E. An elective course on pharmacy-based health screenings. Am J Pharm Educ. 2013;77(6):Article 131.

2. Hess Karl M, Gabrielian C, Schartzman E, et al. The impact of student pharmacists at health fair events. Am J Pharm Educ. 2012;76(8): Article 149.

3. Bastianelli KMS, Nelson L, Palombi L. Perceptions of pharmacists' role in the health care team through student-pharmacist led point-of-care screenings and its future application in health care. Curr Pharm Teach Learn. 2017;9(2): 195-200.

4. Accreditation Council for Pharmacy Education. Accreditation standards and key elements for the professional program in pharmacy leading to the doctor of pharmacy degree. https://

www.acpeaccredit.org/pdf/Standards2016FINAL.pdf. Accessed December 6, 2017.

5. Medina MS, Plaza CM, Stowe CD, et al. Center for the Advancement of Pharmacy Education 2013 educational outcomes. Am J Pharm Educ. 2013;77(8):Article 162.

6. Threatt T, Ward E, Shealy K, et al. Student pharmacist perceived benefit of a sequential training model for health testing. Curr Pharm Teach Learn. 2017;9(2):324-331.

7. McCohana JL, Berdine HJ, Skomo M. Implementation of a student pharmacist-directed cardiovascular risk-reduction screening event. Curr Pharm Teach Learn. 2013; 5:269-275.

8. Sorkin DH, Ngo-Metzger Q, De Alba I. Racial/ethnic discrimination in health care: impact on perceived quality of care. $J$ Gen Intern Med. 2010;25(5):390-396.

9. Siddaiah R, Roberts JE, Graham L, et al. Community health screenings can complement public health outreach to minority immigrant communities. Progress in Community Health Partnerships: Research, Education, and Action. 2014;8(4):433-439. 10. Beach MC, Price EG, Gary TL, et al. Cultural competency: a systematic review of health care provider educational interventions. Med Care. 2005 Apr; 43(4):356-373. 